IP Periodica Polytechnica Civil Engineering

\author{
62(2), pp. 308-317, 2018 \\ https://doi.org/10.3311/PPci.10684 \\ Creative Commons Attribution (i)
}

RESEARCH ARTICLE

\section{Providing Laboratory Rutting Models for Modified Asphalt Mixes with Different Waste Materials}

\author{
Ali Reza Azarhoosh ${ }^{1 *}$, Gholam Hossein Hamedi ${ }^{2}$, \\ Hossein Fallahi Abandansari ${ }^{3}$
}

Received 01 March 2017; Revised 11 August 2017; Accepted 19 September 2017

\begin{abstract}
Due to the complex behavior of asphalt pavement materials under various loading conditions, pavement structure, and environmental conditions, accurately predicting the permanent deformation of asphalt pavement is difficult. This study discusses the application of artificial neural network (ANN) and the multiple linear regression (MLR) in predicting permanent deformation of asphalt concrete mixtures modified by waste materials (waste plastic bottles and waste high-density polyethylene). The use of waste materials in the pavement industry can prevent the accumulation of waste material and environmental pollution and can reduce primary production costs. The results of a laboratory study evaluating the rutting properties of Hot-Mix Asphalt (HMA) mixtures using dynamic creep tests were investigated. The results indicate ANN techniques are more effective in predicting the rutting of the modified mixtures tested in this study than the traditional statistical-based prediction models. On the other hand, results show that an increase in percentage of waste materials is very effective in reducing the final strain of asphalt mixtures. However, an increase in percentage of additives over 7\% does not help to reduce permanent deformation under dynamic loading in the asphalt mixtures.
\end{abstract}

\section{Keywords}

rutting, waste plastic bottles, waste high-density polyethylene, artificial neural networks, multiple linear regressions

\footnotetext{
1 Department of Civil \& Environmental Engineering,

Amirkabir University of Technology, Tehran, Iran

2 Faculty of Engineering, Department of Civil Engineering,

University of Guilan, P.O.Box 3756, Rasht, Iran

2 Department of Civil Engineering, Ayatollah Amoli Branch,

Islamic Azad University, Amol, Iran

* Corresponding author, email: a.r.azarhoosh@aut.ac.ir
}

\section{Introduction}

In recent years, along with the increased volume of heavy traffic in roads, rutting effect has become one of the most important failures, especially in tropical regions. Rutting refers to the longitudinal depressions which are formed by passing vehicles beside their wheel tracks [1].

Rutting could happen in almost all stages of the pavements' life span. Two main mechanisms exist that cause rutting. The first one is pavement densification, i.e. decrease in mass and increase in density. This form of rutting is caused by the compaction and gradual jamming of asphalt and its lower layers, which in turn is caused by the constant flow of vehicles passing on the road. In this case, the main cause of rutting formation would be the weakness of lower layers, including sub-grades. Such wide ruts $(0.75 \mathrm{~m}$ to $1 \mathrm{~m})$ are shallow and lack cracks [2]. The second stage is shear deformation: plastic flow with no change in the volume. Rutting is caused by the lateral movement of asphalt mixtures under shear stress, which is in turn caused by the passage of vehicles. Rutting is mainly caused by weakness in the shear strength of asphalt in this case. In this form of rutting, the materials of asphalt mixture are laterally moved and cause depression in the loading area. In this case, bumps are formed beside wheel tracks [2].

Asphalt binder is one of main materials in asphalt which works as the binder for sticking aggregates together. Tendency towards rutting in asphalt mixtures is very much affected by stiffness and the amount of asphalt binder. Several studies have proved the role of asphalt binder in rutting. With an increase in the stiffness of asphalt binder, an increase can be observed in the stiffness of asphalt mixtures and, as a result, in the strength against rutting. However, with the increased traffic volumes and vehicle loads, there is a need to improve conventional asphalt binder properties, particularly the resistance to the permanent deformation of pavement in the form of rutting.

ANNs are widely accepted as an information processing methodology which is inspired by the working process of the human brain. ANNs are efficient in handling the nonlinear relationship in data [3]. The empirical models and correlations developed by conventional methods are complex in nature, 
difficult to predict non-linear relationship, and less accurate and also require long computation time. The ANN has numerous advantages, including the accurate approximations of complex problems, greater efficiency than phenomenological models, even for multiple response computations, and greater effectiveness even with incomplete and noisy input data [4].

\subsection{Literature review}

To date, few studies have been conducted on rutting models of modified asphalt mixtures with waste materials. Several studies have shown that HMA mixtures containing polymermodified asphalt binders are more rut resistant than mixtures with neat asphalt binders [5-9]. Modified asphalt binders can be designed to satisfy pavement service conditions at both high and low temperature extremes.

Punith and Veeraragavan [5] used reclaimed polyethylene (PE) as an additive in asphalt concrete mixtures. They found that the performance of PE-modified asphalt mixtures are better when compared to conventional mixtures. The rutting potential and temperature susceptibility can be reduced by the inclusion of PE in the asphalt mixture. In another study, Moghadas Nejad et al. [6] investigated the potential use of high-density polyethylene (HDPE) on performance characteristics of asphalt mixtures such as fatigue cracking and rutting. The results show that fatigue life is higher in mixtures containing HDPE than those for control mix. Also, HDPE-modified mixtures provide better resistance to rutting due to their higher stiffness. In addition, by increasing the temperature and fatigue life, resistance to permanent deformation of all specimens decreased, where sensitivity to temperature is lower in mixes containing HDPE.

Also, Willis et al. [7] compared results of the dynamic modulus test, asphalt pavement analyzer, flow number, bending beam fatigue, indirect tension creep compliance and strength test, energy ratio, and moisture susceptibility of control mix (without polymer) and modified mixtures (high polymer mixtures). The laboratory test results of this research suggest that high polymer mixtures can be placed to develop more efficient (i.e. thinner) pavement cross-sections due to their enhanced fatigue and rutting resistance.

Based on previous studies, waste plastic bottles (PB) has a great potential to be reused as modifier in asphalt mixture. Results indicated that adding PB to asphalt improved the fatigue behavior of studied mixes [8]. During a laboratory study Abdelaziz and Mohemad [9] examined the effect of different PB contents on the rheological properties of modified asphalt binder. They found that addition of PB to asphalt binder will increase the viscosity and reduce the temperature susceptibility of modified asphalt binder. Furthermore, the PB modified asphalt binder showed preferable elastic properties than the original one (i.e. higher complex modulus and lower phase angle).

Although many researches have been worked in this field, however, in some cases, the physics and the mechanics of rutting problem are still not fully understood, hence, it is too complicate to explain it mathematically [10]. In recent years, many efforts have been made to use various methods to develop a model for predicting the rutting potential of asphalt mixtures considering different effective parameters. Increasingly, modern pattern recognition techniques such as neural network, genetic algorithms, and fuzzy logic are being investigated to develop models from the data to give the capability of learning and recognition of data patterns [11]. ANN method has had an increasing use in physical models of analyzing complex relationships involving multiple variables in civil engineering areas [12]. Due to the above-mentioned features, the ANN techniques have been adopted by some researchers to predict the performance of pavements [12-16].

\subsection{Objectives}

The objective of this research was to investigate the rutting of HMA mixtures containing waste materials as an asphalt binder modifier. Dynamic creep test was used to assess the rutting of control (without waste materials) and modified asphalt samples. The behaviour of the mixtures was compared with each other and the effect of each mixture parameter was investigated.

The specific objectives of this study are to:

- Study the effect of waste materials on the asphalt binder properties.

- Evaluating the behaviour of HMA mixtures under dynamic creep test with and without waste materials.

- Offering the rutting model using MLR \& ANN.

\section{Materials}

\subsection{Aggregate and asphalt binder}

Locally available limestone aggregates have been used in this study to prepare mixtures. The physical properties of the aggregate that was used in this study are listed in Table 1. The gradation of the aggregates used in the study (mean limits of ASTM specifications for dense aggregate gradation) is given in Table 2. The nominal size of this gradation was $12.50 \mathrm{~mm}$. Conventional test methods such as the penetration test, softening point test and ductility were performed to characterize the properties of the base asphalt binder. The engineering properties of the asphalt binder are presented in Table 3.

\subsection{Additives}

Waste polyethylene (PE) is the most popular plastic in the world. This material is a semi crystalline material with excellent chemical resistance, good fatigue and wear resistance and a wide range of properties. It has a very simple structure. A molecule of PE is a long chain of carbon atoms, with two hydrogen atoms attached to each carbon atom. They are light in weight and provide good resistance to organic solvents with low moisture absorption rates [17]. One type of PE grade was 
Table 1 Physical properties of the aggregate

\begin{tabular}{|c|c|c|c|}
\hline Test & Standard & Limestone & Specification limit \\
\hline Specific gravity (coarse agg.) & ASTM C 127 & & \\
\hline Bulk & & 2.615 & ----- \\
\hline SSD & & 2.644 & ---- \\
\hline Apparent & & 2.661 & ---- \\
\hline Specific gravity (fine agg.) & ASTM C 128 & & \\
\hline Bulk & & 2.622 & ---- \\
\hline SSD & & 2.636 & ---- \\
\hline Apparent & & 2.654 & ---- \\
\hline Specific gravity (filler) & ASTM D854 & 2.642 & ---- \\
\hline Los Angeles abrasion (\%) & ASTM C 131 & 27 & $\operatorname{Max} 45$ \\
\hline Flat and elongated particles (\%) & ASTM D 4791 & 8.5 & $\operatorname{Max} 10$ \\
\hline Sodium sulfate soundness $(\%)$ & ASTM C 88 & 5.69 & $\operatorname{Max} 10-20$ \\
\hline Fine aggregate angularity & ASTM C 1252 & 45.44 & Min 40 \\
\hline
\end{tabular}

Table 2 Gradation of the aggregates used in the study

\begin{tabular}{lccccc}
\hline Sieve $(\mathrm{mm})$ & 19 & 12.5 & 4.75 & 2.36 & 0.3 \\
\hline Lower-upper limits & 100 & $90-100$ & $44-74$ & $28-58$ & $5-21$ \\
Passing (\%) & 100 & 95 & 59 & 43 & 13 \\
\hline
\end{tabular}

Table 3 Results of the experiments conducted on 60/70 penetration grade asphalt binder

\begin{tabular}{llc}
\hline Test & Standard & Result \\
\hline Penetration $\left(100 \mathrm{~g}, 5 \mathrm{~s}, 25^{\circ} \mathrm{C}\right), 0.1 \mathrm{~mm}$ & ASTM D5 \\
Penetration $\left(200 \mathrm{~g}, 60 \mathrm{~s}, 4{ }^{\circ} \mathrm{C}\right), 0.1 \mathrm{~mm}$ & ASTM D5 \\
Penetration ratio & ASTM D5 \\
Ductility $\left(25^{\circ} \mathrm{C}, 5 \mathrm{~cm} / \mathrm{min}\right), \mathrm{cm}$ & ASTM D113 \\
Solubility in trichloroethylene, $\%$ & ASTM D2042 \\
Softening point, ${ }^{\circ} \mathrm{C}$ & ASTM D36 \\
Flash point, ${ }^{\circ} \mathrm{C}$ & ASTM D92 \\
Loss of heating, $\%$ & ASTM D1754 \\
\hline
\end{tabular}

used in this research, the physical and chemical properties of which are shown in Tables 4 and 5, respectively. All the waste HDPE particles passed a No.10 $(2 \mathrm{~mm})$ sieve and were retained on a No.40 $(0.42 \mathrm{~mm})$ sieve in powder form. HDPE offers excellent impact resistance, light weight, low moisture absorption and high tensile strength [17].

Waste PB is a type of polyester material, and is often used for packing in food and beverage industries. Waste PB was obtained from plastic bottles. For utilization of $\mathrm{PB}$ as additive in asphalt mixtures the bottles were cut to small parts, thereafter crushed by crushing machine. The crushed plastic bottles particles were sieved, and the par particles passing sieve $2.36 \mathrm{~mm}$ were used for this investigation. Tables 4 and 5 depict physical and chemical properties of PB material.

\section{Experimental setup and procedure}

\subsection{Mix design}

In this study, five HDPE and PB concentrations (2, 4, 6, 8 and $10 \%$ ), with respect to the weight of base asphalt, were selected. A total of 165 mix design were conducted which includes 150 mix designs for modified mixtures ( 2 different types of waste material additives $\times 5$ different percentage of additives $\times 3$ test temperatures $\times 5$ stresses) and 15 mix design for conventional mixtures ( 3 test temperatures $\times 5$ stresses).

Modified asphalts with different PB and HDPE concentrations were produced through a mechanical shearing process. Firstly, the base asphalt was heated to $180{ }^{\circ} \mathrm{C}$ to make it fully melted, and then the PB and HDPE were added to the asphalt in sequence, with a shearing speed of $2000 \mathrm{r} / \mathrm{min}$ for $20 \mathrm{~min}$. After this, the mixtures were stirred at a speed of $5000 \mathrm{r} / \mathrm{min}$ for $1.5 \mathrm{~h}$ at $180{ }^{\circ} \mathrm{C}$ and followed by a $20 \mathrm{~min}$ low speed $(<100$ $\mathrm{r} / \mathrm{min}$ ) stirring to exclude the air introduced by the high speed shearing process.

Finally, the asphalt mixtures were designed using the standard Marshal mix design. Two series of Marshall specimens were fabricated. The first series of the specimens contained several asphalt binder contents to determine the optimal asphalt binder content. The second series were at the optimal asphalt binder content to evaluate the HMA mechanistic properties.

The optimum asphalt binder content for the mix design was determined by taking the average values of the following three asphalt binder contents: 
(1) Asphalt binder content corresponding to maximum stability.

(2) Asphalt binder content corresponding to maximum bulk specific gravity.

(3) Asphalt binder content corresponding to the median of designed limits of percent air voids in the total mix.

The stability value, flow value, and voids filled with asphalt binder (VFA) are checked with the Marshall mix design specification. The optimum asphalt binder contents were found to be $5.1 \%$.

\subsection{Conventional tests}

Penetration test at $25^{\circ} \mathrm{C}$ and softening point test were conducted to characterize the conventional physical properties of asphalts, according to ASTM D5, ASTM D36, respectively. The effects of PB and HDPE content on the asphalts' penetration and softening point were shown in Figure 1.
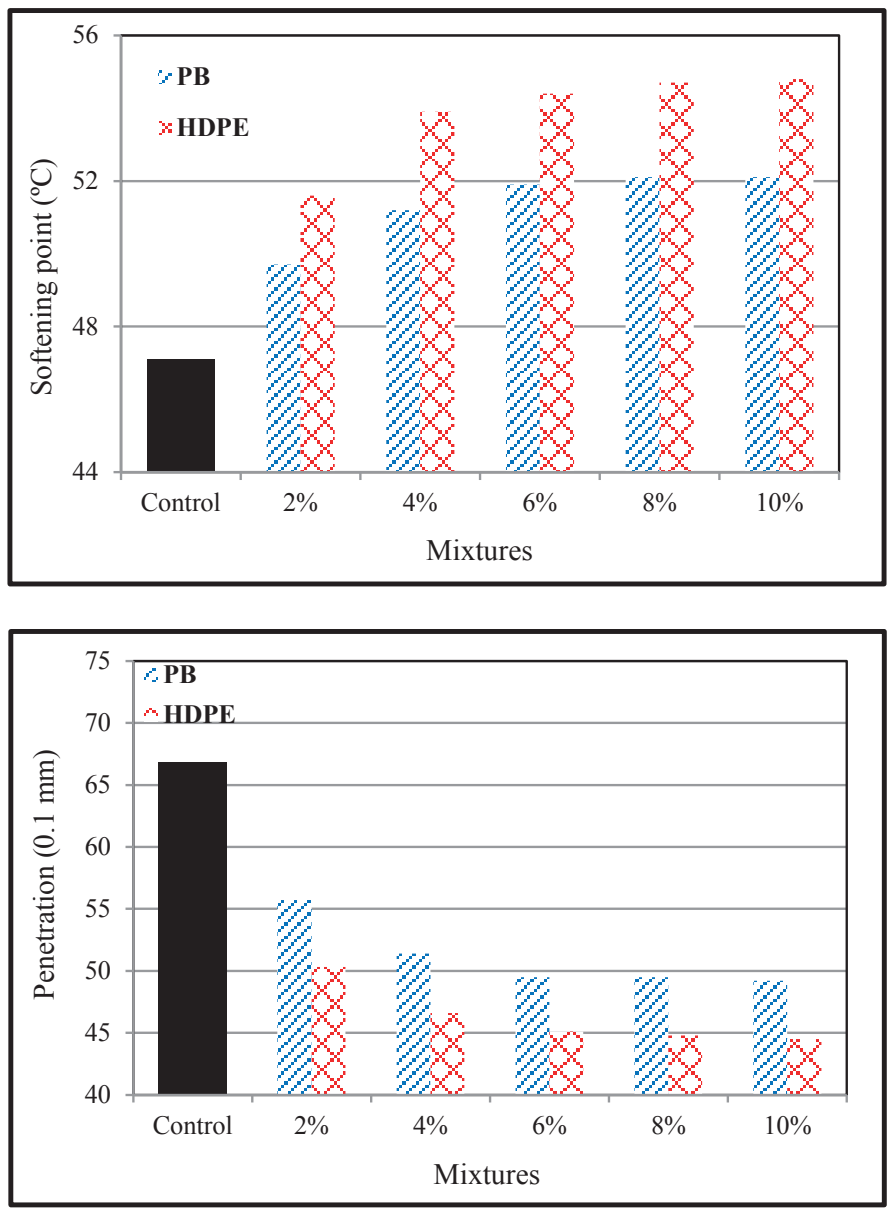

Fig. 1 Conventional tests results of modified asphalt binder

As presented in this figure, while the softening point increases with increasing HDPE and PET in separate samples, the penetration has a decreasing trend. Polymer modification increases the viscosity of the asphalt binder, and this increase in viscosity causes a corresponding increase in tensile and compressive strengths of the HMA.
Table 4 Physical properties of HDPE and PB

\begin{tabular}{lccc}
\hline Test & Standard & HDPE & PB \\
\hline Density $\left(\mathrm{g} / \mathrm{cm}^{3}\right)$ & D792 & 0.97 & 1.24 \\
Water Absorption, 24 hours (\%) & D570 & 0 & 0 \\
Tensile Strength (MPa) & D638 & 23.6 & 55.7 \\
Tensile Elongation at Yield (\%) & D638 & $820-850$ & $980-1100$ \\
\hline
\end{tabular}

Table 5 Chemical composition of HDPE and PB

\begin{tabular}{lcc}
\hline Properties & HDPE & PB \\
\hline $\mathrm{pH}$ & 8.1 & 7.4 \\
Silicon dioxide, $\mathrm{SiO}_{2}(\%)$ & 65.1 & 69 \\
$\mathrm{R}_{2} \mathrm{O}_{3}\left(\mathrm{Al}_{2} \mathrm{O}_{3}+\mathrm{Fe}_{2} \mathrm{O}_{3}\right)(\%)$ & 17.9 & 19 \\
Aluminum oxide, $\mathrm{Al}_{2} \mathrm{O}_{3}(\%)$ & 13.2 & 12.1 \\
Ferric oxide, $\mathrm{Fe}_{2} \mathrm{O}_{3}(\%)$ & 4.7 & 6.9 \\
Magnesium oxide, $\mathrm{MgO}(\%)$ & 1.8 & 1.9 \\
Calcium oxide, $\mathrm{CaO}(\%)$ & 3.4 & 2.6 \\
\hline
\end{tabular}

\subsection{Dynamic creep test}

The dynamic creep experiment has been used for a long time to determine the rutting potential of asphalt, which is due to its simplicity and logical relation with permanent deformation of the asphalt mixture. The main purpose of this experiment is constricted to the classification of materials and their comparison in the area of rutting potential. In other words, rutting depth determination using this experiment is not possible. The most important outcome of the dynamic creep experiment is the accumulative strain curve facing the number of loading cycles which depends on the compound rutting strength. Figure 1 depicts a form of this curve [18].

As shown in Figure 2, the curve is made of 3 major parts: primary zone, in which permanent deformations are quickly accumulated, the secondary zone, in which accumulative strains are increased with a smooth and constant slope, and the tertiary zone, in which the tone of increase in accumulative strain is again increased. The first zone could be identified as a first rutting mechanism (densification; decrease of mass and increase of density). The second zone could be identified as a connector of the two zones. The third zone could be identified as the second rutting mechanism (shear deformation; plastic flow with no change in the volume) [19].

The dynamic creep test applies a repeated pulsed uniaxial stress on an asphalt specimen and measures the resulting deformations in the same direction using linear variable differential transducers (LVDTs) [20]. The tests were performed according to the following procedure. The specimens were placed in the loading machine under a conditioning stress of $10 \mathrm{KPa}$ for 600 seconds. Then, the conditioning stress was removed and a stresses of 100-500 KPa were applied for 10000 cycles with 0.1 second loading and 0.9 second rest periods, after which the axial deformation was measured during the creep test using LVDTs. The temperatures of the test were considered equal to 40,50 and $60^{\circ} \mathrm{C}$. 


\section{Artificial neural networks (ANN)}

Artificial neural networks constitute a branch of artificial intelligence which has recently undergone rapid evolution and progress [21]. ANNs act as a black box model, which are composed of interconnected processing units called artificial neurons or nodes [3]. The ANN approach has the ability to learn highly non-linear relationships and process information by its dynamic system response to external inputs [4]. But ANN is not an equation fitting model.

Whereas there are several types of ANNs such as recurrent, radial basis, function networks, and self-organizing maps, the most commonly implemented type of ANNs are multilayer feed forward neural networks (FFNN), which was used in this study. The multilayer feed forward neural network consists of an input layer, one or more hidden layers, and an output layer $[3,22]$. In this set of networks, information is only transmitted in the forward direction from the input layer to the hidden layer(s) and to the output layer [22]. The number of input and output physical quantities specifies the number of the neurons in the input and output layers [3, 22]. In this study, the input layer was composed of 4 nodes, which were additive type, additive content, temperature, and stress. The output layer had one node, which was the final strain of asphalt mixtures. There is no general rule for determining the optimum number of nodes in the hidden layer and it is usually determined through trial and error [3, 22-24].

The nodes between each layer were connected with adaptable weights. The general working principle of the artificial neuron or node can be demonstrated as [3]:

$$
y_{i}=f\left(\sum_{j=1}^{n} x_{j} w_{i j}+b_{i}\right)
$$

where $x_{j}$ is the input from the previous node $j, w_{i j}$ is the weight that connects node $i$ and node $j, n$ is the total number of previous nodes connecting to node $i, b_{i}$ is the bias of node $i$, and $f$ is activation (transfer) function. The hyperbolic tangent sigmoid (tansig) function and the linear (purelin) function are commonly used activation functions. The tansig function is used for non-linear relationship approximation and the purelin function is used for linear relationship approximation [3]. Feed forward neural networks with one hidden layer can virtually approximate any linear or non-linear function to an acceptable accuracy, if sufficient hidden layer nodes are provided with the sigmoid function as the hidden layer activation function and the linear function as the output layer activation function [3]. In this study, the tansig and purelin functions were used as the activation functions in the hidden layer and the output layer, respectively. Therefore, a feed forward neural network with one hidden layer was applied to predict the experimental data in this work.

Before using any method for training, an ANN has to normalize input and output. So, input and output data were normalized between -1 and 1 by the following equation:

$$
\begin{aligned}
& \text { Normalized value }= \\
& \frac{2\left[(\text { Actual })_{\text {value }}-(\text { minimum })_{\text {Actual value }}\right]}{(\text { maximum })_{\text {Actual value }}-(\text { minimum })_{\text {Actual value }}}-1
\end{aligned}
$$

Training is a method for calculating weight and bias. During training, the network works in an iterative method until producing a new output. There are different kinds of training methods, among which back-propagation is a common method [21].

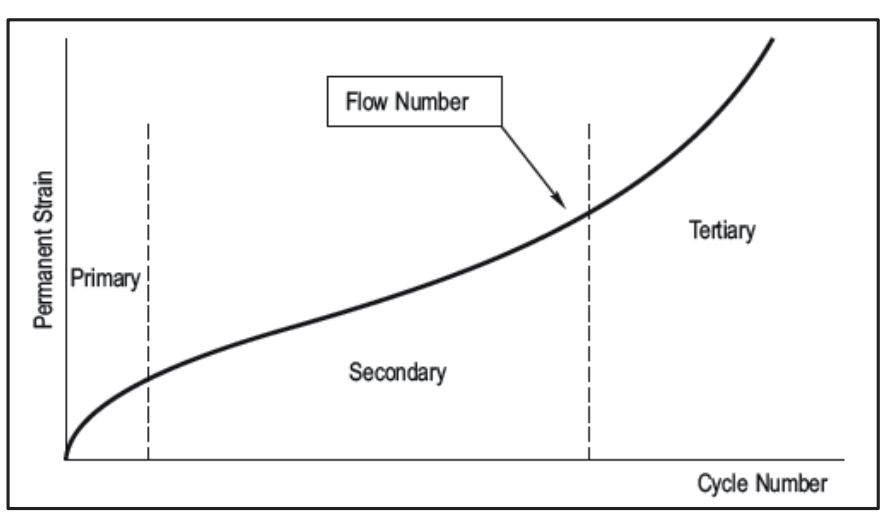

Fig. 2 Typical flow number test result

The multilayer feed forward neural networks with backpropagation structure were implemented using different learning rules in the neural network approach such as Bayesian regulation (BR), Levenberg-Marquardt (LM), Scaled conjugated gradient (SCG) and RPROP back propagation (RP). In the Bayesian regulation rule, the input data were divided into two parts; $70 \%$ and $30 \%$ of the data were used for training and test, respectively, but in other learning rules the input data were divided into three parts; $70 \%, 15 \%$ and $15 \%$ of the data were used for training, validation and test, respectively. The number of data used in the network is 165 . The results of the network models for different neuron numbers in the hidden layer using different training algorithms are presented in Table 7. The correlation performance of the network is assessed by using root mean square error (RMSE) and correlation coefficient $\left(\mathrm{R}^{2}\right)$ values.

In this study, the input layer is composed of 4 nodes, which are the stress, temperature, additive type and content. The output layer has one node, which is final strain. There is no general rule for the determination of the optimum number of nodes in the hidden layer and usually it is determined through trial and error. It can be seen that the Levenberg-Marquardt back propagation algorithm with 10 neurons in the hidden layer is the best training procedure that achieved the highest $\mathrm{R}^{2}$ and lowest RMSE. Thus, the optimum number of neurons is used to create the network topologies which were 4-10-1. Here, the numbers in the expressions of the network topologies represent the neuron numbers in the input layer, the hidden layer and the output layer, respectively. The schematic diagram of ANN model selected for the current study is shown in Figure 3. 
Table 6 Conventional tests results of modified asphalt binder

\begin{tabular}{|c|c|c|c|c|c|c|c|c|c|}
\hline \multirow[t]{2}{*}{ Learning rule } & \multirow[t]{2}{*}{ No. of neurons } & \multicolumn{4}{|c|}{$\mathrm{R}^{2}$} & \multicolumn{4}{|c|}{ RMSE } \\
\hline & & Train & Validation & Test & Mean & Train & Validation & Test & Mean \\
\hline \multirow[t]{3}{*}{ LM } & 5 & 0.993 & 0.9887 & 0.994 & 0.9924 & 0.0315 & 0.0374 & 0.0265 & 0.0312 \\
\hline & 10 & 0.999 & 0.9971 & 0.991 & 0.9973 & 0.0127 & 0.0231 & 0.0332 & 0.0188 \\
\hline & 15 & 0.998 & 0.9895 & 0.992 & 0.9963 & 0.0147 & 0.0374 & 0.0255 & 0.0216 \\
\hline \multirow[t]{3}{*}{ BR } & 5 & 0.997 & - & 0.992 & 0.9954 & 0.0206 & - & 0.0307 & 0.0241 \\
\hline & 10 & 1.000 & - & 0.985 & 0.9959 & 0.0047 & - & 0.0424 & 0.0234 \\
\hline & 15 & 1.000 & - & 0.988 & 0.9953 & 0.0020 & - & 0.0447 & \\
\hline \multirow[t]{3}{*}{ SCG } & 5 & 0.981 & 0.9643 & 0.976 & 0.9766 & 0.0529 & 0.0608 & 0.0583 & 0.0548 \\
\hline & 10 & 0.985 & 0.9774 & 0.931 & 0.9791 & 0.0436 & 0.0714 & 0.0624 & 0.0520 \\
\hline & 15 & 0.986 & 0.9942 & 0.979 & 0.9869 & 0.0424 & 0.0301 & 0.0400 & 0.0412 \\
\hline \multirow[t]{3}{*}{$\mathrm{RP}$} & 5 & 0.929 & 0.9574 & 0.918 & 0.9268 & 0.1015 & 0.0700 & 0.0989 & 0.0969 \\
\hline & 10 & 0.986 & 0.9817 & 0.953 & 0.9819 & 0.0447 & 0.0332 & 0.0707 & 0.0480 \\
\hline & 15 & 0.990 & 0.9687 & 0.955 & 0.9803 & 0.0332 & 0.0800 & 0.0707 & 0.0500 \\
\hline
\end{tabular}

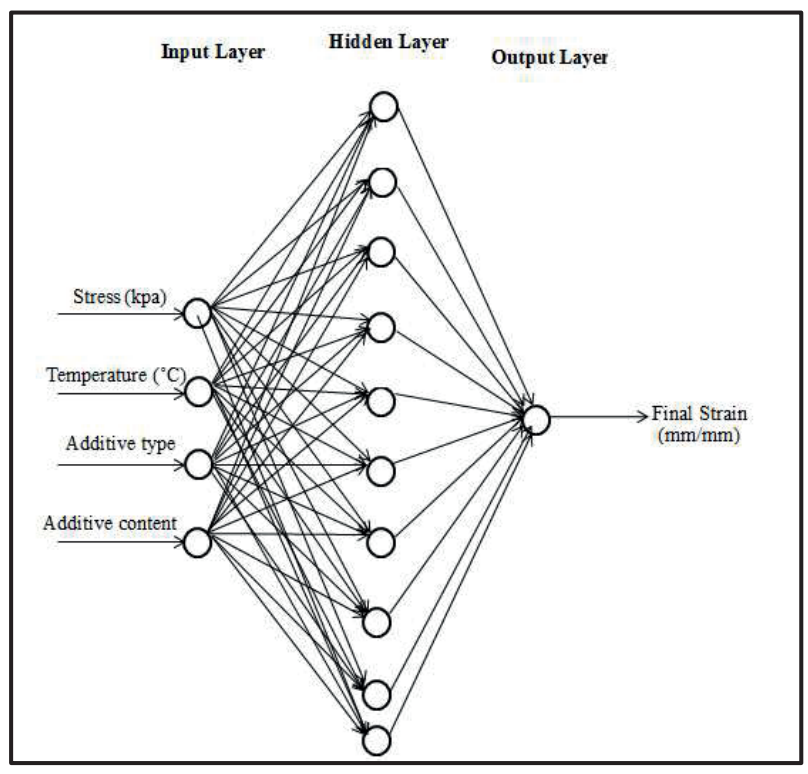

Fig. 3 Artificial neural network structure used in this study

\section{Results and discussion}

\subsection{MLR model results}

In this section, the traditional rutting models for two additive types, obtained through liner regression analysis, were presented. These models used additive content, temperature, and stress as input variables which are shown in Equations 3 and 4.

$$
\begin{gathered}
\varepsilon_{P B}=-8.2609 \times 10^{-4} \mathrm{C}+2.3163 \times 10^{-4} T+2.9359 \times 10^{-5} S \\
\varepsilon_{H D P E}=-8.6712 \times 10^{-4} \mathrm{C}+2.3480 \times 10^{-4} \mathrm{~T}+2.8095 \times 10^{-5} S \\
0 \leq C \leq 2 \%, 40 \leq T \leq 60^{\circ} \mathrm{C} \text { and } 100 \leq S \leq 500 \mathrm{kPa}
\end{gathered}
$$

where $\varepsilon_{P B}, \varepsilon_{H D P E}, C, T$ and $S$ are final strain $(\mathrm{mm} / \mathrm{mm})$, additive content $(\%)$, temperature $\left({ }^{\circ} \mathrm{C}\right)$ and stress $(\mathrm{kPa})$, respectively. Use the final strain values of $2 \%$ additive content for more quantities.

Figure 4 shows comparison plots between the model output and its corresponding experimental data. The results indicate a poor fit between experimental and predicted data with low coefficient of determination. Thus, the final strain prediction of using these traditional models may not be reliable.

\subsection{ANN model results}

The multilayer feed forward neural network with backpropagation structure using Levenberg-Marquardt's learning rule with 10 neurons in the hidden layer was selected as the optimum network. Figure 5 explains comparison plot between the optimum network output and its corresponding experimental data of the strain of conventional and modified asphalt mixtures for training (Fig. 5-a), validation (Fig. 5-b), testing (Fig. 5-c) and overall (Fig. 5-d) data. This figure shows that this ANN model had a perfect fit and the predicted values comes in a good agreement with the experimental values inferring that the model was successfully developed to capture the correlation between effective factors of rutting and final strain.

Figure 6 shows the performance graph. It is observed that the best validation performance is at epoch 14 and the validation error is increased after this epoch. So, the training operation stops after 6 epochs which is defined in the program. Also, the errors of data attained by the optimum ANN model were plotted out versus the frequency of data in figure 7. A nigh normal distribution of variation brings about a specific bell-shaped curve (Gaussian curve), with the highest point about in the middle and smoothly curving symmetrical slopes on both sides of center. This figure illustrates an approximately normal distribution of errors produced by the model. The Gaussian curve reveals that our results are symmetrical approximately [22].

The predicting performance of the trained neural network as shown in Figure 5 is considered satisfactory and significance improvement (in terms of $\mathrm{R}^{2}$ ) over those obtained by regression analyses as presented in Figure 4 is achieved. The overall correlation coefficient for ANN method was equal to 0.9973; but, traditional statistical-based prediction models had less correlation coefficient (about 0.76). On the other hand, ANN models, which act like a black box model, can easily be implemented in a spreadsheet, thus, making it easy to apply. 


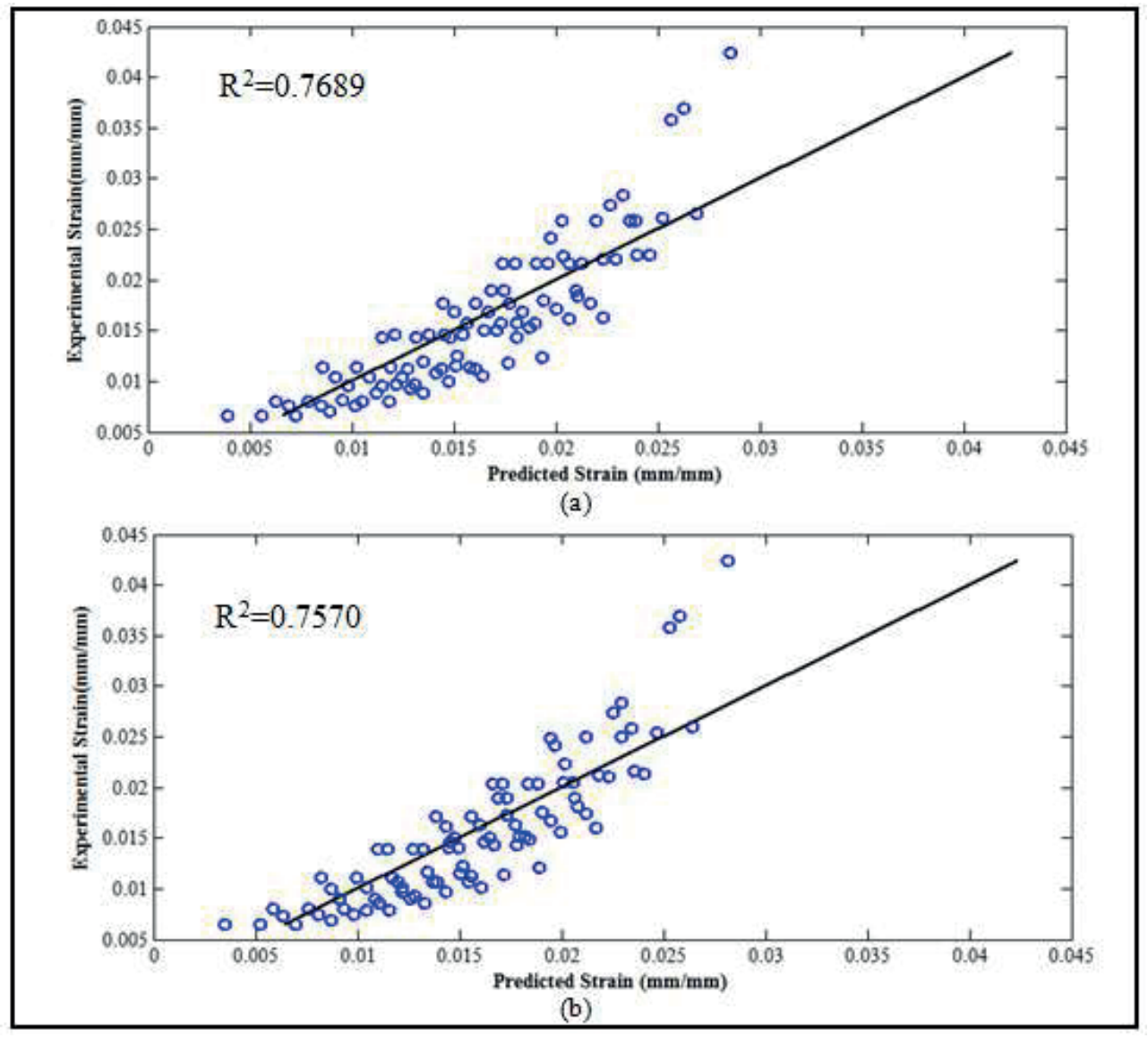

Fig. 4 Comparison between experimental \& MLR model values (a) PB mixtures (b) HDPE mixtures
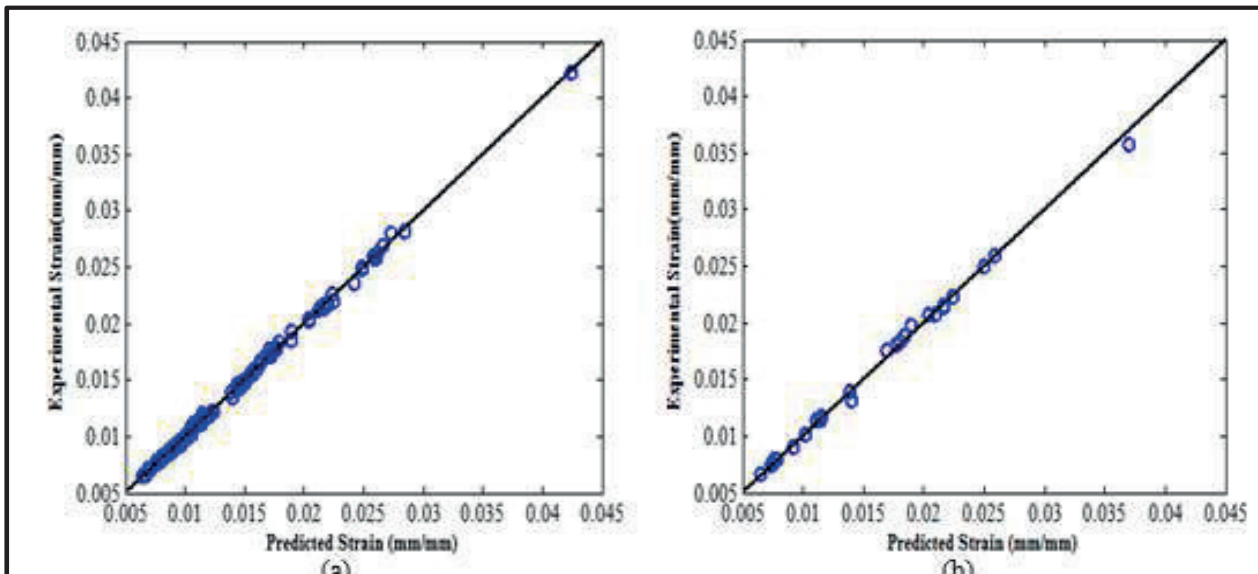

(a)

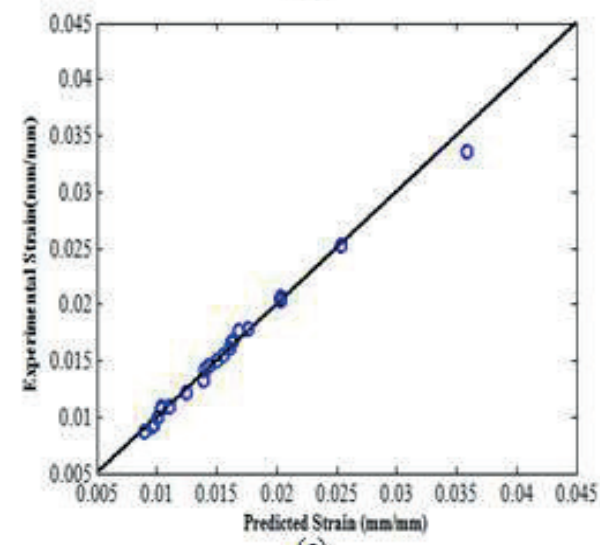

(b)

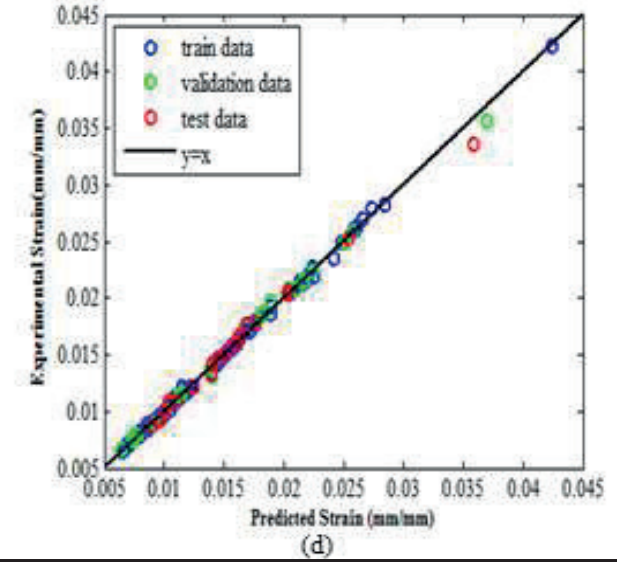

Fig. 5 Comparison between experimental and ANN values in (a) training, (b) validating, (c) testing and (d) overall data sets 


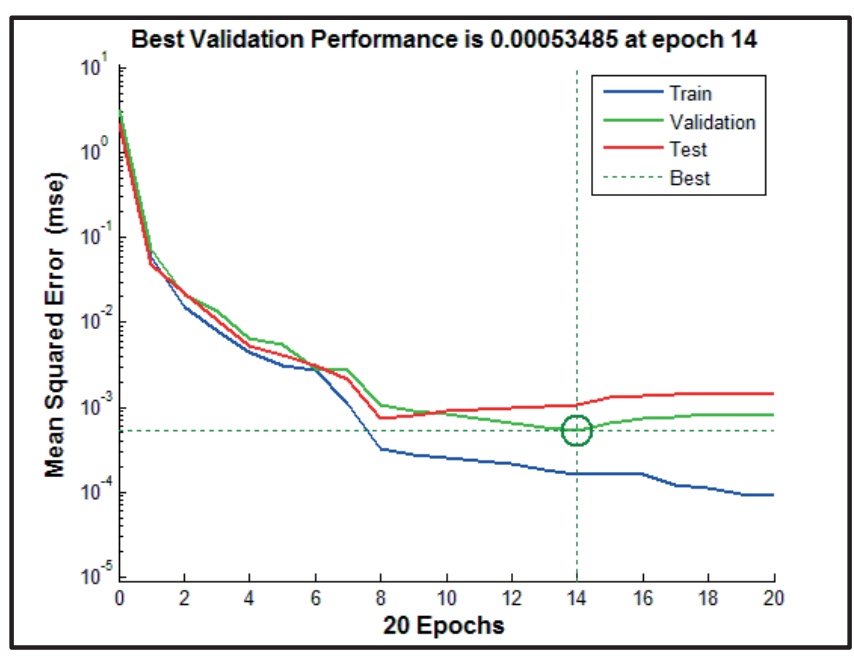

Fig. 6 Performance graph

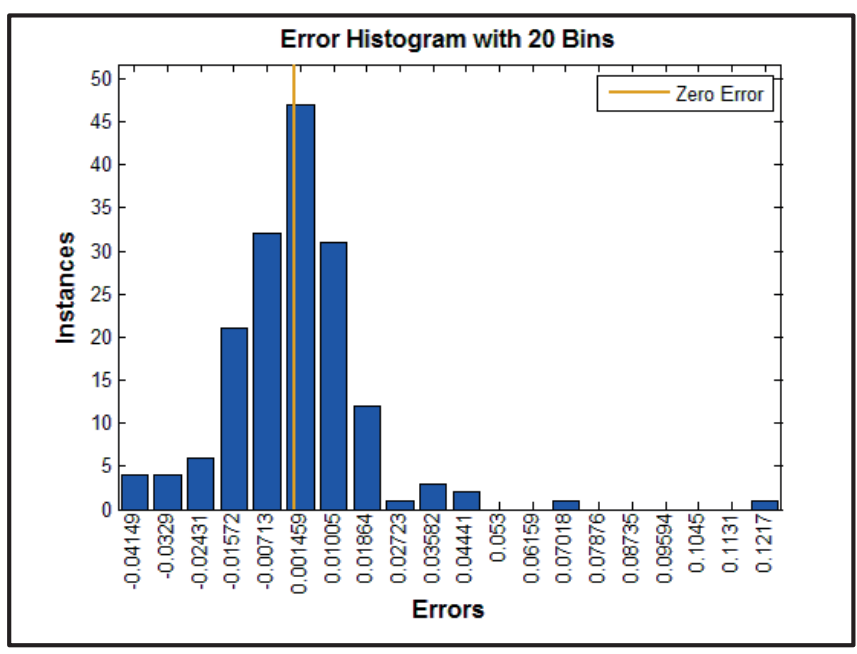

Fig. 7 Error histogram

\subsection{Influenced of additive content on permanent deformation}

Although there are four input parameters in the model, it is more meaningful to investigate the influence of input parameters on the strain [13]. For this purpose, the developed ANN model is used to simulate the effect of some factors such as additive content and temperature on strain of asphalt mixture. To this, end one input parameter was changed slightly (approximately $1 \%$ ) when the remaining parameters were kept constant. Then the predicted final strain was determined. Thus for each additive type, the stress was kept at $300 \mathrm{kPa}$. Figures 8 and 9 illustrate the variations in strain with increasing additive content in different temperatures for PB and HDPE, respectively. As shown in these figures, the temperature rise leads to an increase in rutting potential in control and modified asphalt samples; asphalt binder's high sensitivity to changes of temperature being the cause. With an increase in temperature, the viscosity and stiffness of asphalt binder descends and makes it softer. These factors are in agreement with Strategic Highway Research Program (SHRP) qualification for the rutting property [25]. On one hand, additives decrease the temperature sensitivity of the asphalt binder by decreasing its penetration and increasing its softening point.
On the other hand, the procedure of changes in permanent deformation at any temperature follows the last model, but the level of influence of additives in decreasing deformation is more significant in higher temperatures than in lower ones.

Additionally the value of final strain at a specific temperature and stress for modified samples was less than conventional samples for both additive types. Therefore, the modified specimens had less permanent deformation than the conventional samples. This means that the additive particles make the binders stiffer at the maximum pavement service temperature and are beneficial in improving the resistance of permanent deformation. In addition, it can be concluded that the influence of HDPE on decrement of strain is greater than that of $\mathrm{PB}$, and this subject leads to more resistant against plastic deformation (rutting) in samples containing HDPE, compared with samples modified by PB.

It can be seen that as the additives content increases to $1 \%$, the strain value tend to decrease drastically. As the additive increases, the penetration and softening point of the modified asphalt binder are significantly reduced and increased compared to the base asphalt binder, respectively. However, further increase in additives content has little effect on enhancing the value of strain at a specific stress in comparison with increasing in additive content. It was also found that the optimum additive content for both additives are determined to be in ranges from $5 \%$ to $7 \%$. However, increase in percentages over $7 \%$ has no effect on reducing permanent deformation in the asphalt mixtures. Therefore the influence of additives content on final strain is quite well understood based on neural network.

\section{Conclusions}

Final strain is affected by several factors (additive type, additive content, temperature, stress, etc), so final strain prediction is quite complex. Due to the complexity of the relationship between input variables and output (final strain), it is difficult to be modeled using traditional mathematical modeling.

In this study, the effects of variables were modeled using MLR and ANN. The multilayer feed forward neural network with back-propagation structure was implemented using different learning rules in the neural network approach. The ANN with a 4-10-1 architecture and Levenberg-Marquardt's learning rule has the best fit and was selected as the optimum ANN model for prediction. The input layer was composed of 4 nodes of additive type, additive content, temperature and stress. Also, the output layer had one node, which was the final strain of asphalt mixtures. The tansig and purelin functions were used as the activation functions in the hidden and output layers, respectively. In the optimum model, the input data were divided into three parts; $70 \%, 15 \%$ and $15 \%$ of the data were used for training, validation and test, respectively.

The results indicate that there is a very good agreement between experimental and predicted results by ANN. Also, the MLR was used to predict final strain for PB \& HDPE 
asphalt mixtures. Also, the results show a poor fit for these objective functions with low coefficient of determination. This confirms the ANN technique is more effective than the traditional statistical-based (MLR) prediction models.

Furthermore, the proposed network is applied to observe the effect of changing in percentage of additive for determining the strain of asphalt samples. The results show that the final strain of asphalt mixtures can be significantly improved through incorporating the maximum of 7\% HDPE and PB into mixtures. That means both the waste-additives would help in reducing rutting potential in asphalt samples. However, increase in additives percentage over $7 \%$ does not help the reduction of permanent deformation in asphalt mixtures. As a result, the optimum additive content for both additive types was determined to be in ranges from $5 \%$ to $7 \%$.

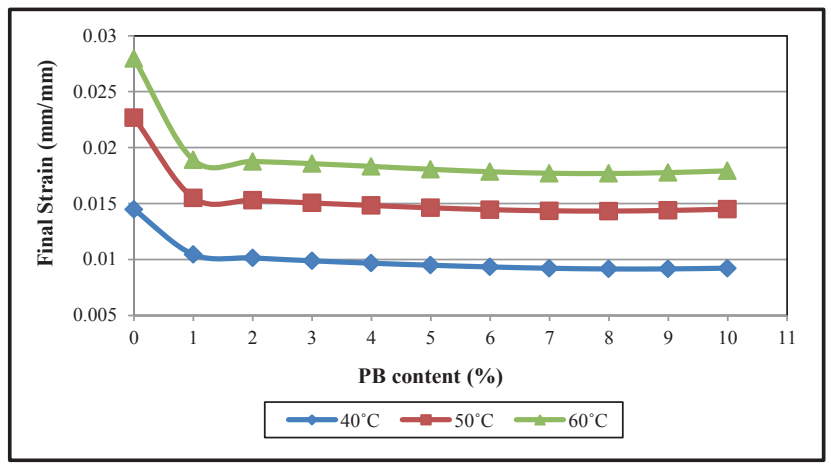

Fig. 8 Effect of $\mathrm{PB}$ on final strain at various temperatures at $300 \mathrm{kPa}$

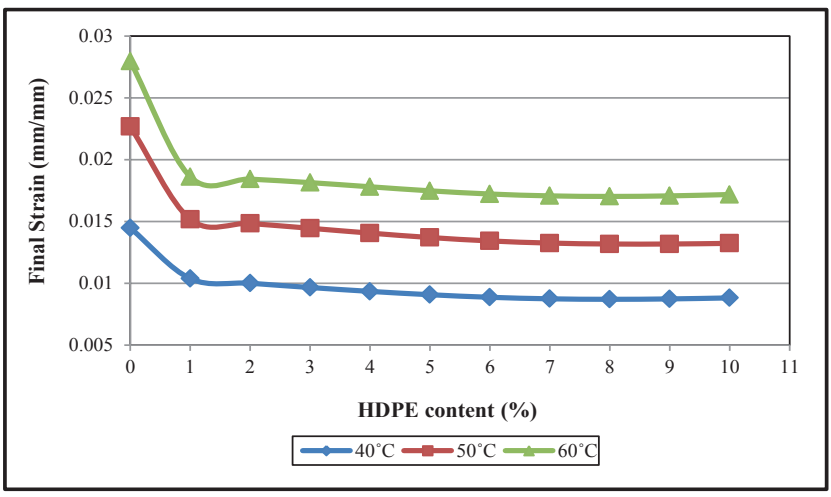

Fig. 9 Effect of HDPE on final strain at various temperatures at $300 \mathrm{kPa}$

\section{References}

[1] Laurinavičius, A., Oginskas, R. "Experimental research on the development of rutting in asphalt concrete pavements reinforced with geosynthetic materials". Journal of Civil Engineering and Management, 12(4), pp. 311-317. 2006. https://doi.org/10.1080/13923730.2006.9636408

[2] Moghadas Nejad, F. M., Azarhoosh, A. R., Hamedi, G. H., Azarhoosh, M. J. "Characterization of permanent deformation resistance of precipitated calcium carbonate modified asphalt mixture". Journal of Civil Engineering and Management, 21(5), pp. 615-622. 2015. https://doi.org/10.3846 $/ 13923730.2014 .890654$

[3] Meng, X., Jia, M., Wang, T. "Neural network prediction of biodiesel kinematic viscosity at 313K". Fuel, 121, pp. 133-140. 2014. https://doi. org/10.1016/j.fuel.2013.12.029
[4] Kamble, L., Pangavhane, D., Singh, T. "Experimental investigation of horizontal tube immersed in gas-solid fluidized bed of large particles using artificial neural network". International Journal of Heat and Mass Transfer, 70, pp. 719-724. 2014. https://doi.org/10.1016/j.ijheatmasstransfer. 2013.11.073

[5] Punith, V., Veeraragavan, A. "Behavior of asphalt concrete mixtures with reclaimed polyethylene as additive". Journal of materials in civil engineering, 19(6), pp. 500-507. 2007. https://doi.org/10.1061/ (ASCE)0899-1561(2007)19:6(500)

[6] Moghadas Nejad, F., Azarhoosh, A. R., Hamedi, G. H. "Effect of high density polyethylene on the fatigue and rutting performance of hot mix asphalt-a laboratory study". Road Materials and Pavement Design, 15(3), pp. 746-756. 2014. https://doi.org/10.1080/14680629.2013. 876443

[7] Willis, J. R., Taylor, A., Tran, N. H., Kluttz, B., Timm, D. H. "Laboratory evaluation of high polymer plant-produced mixtures". Road Materials and Pavement Design, 13(sup1), pp. 260-280. 2012. https://doi.org/1 0.1080/14680629.2012.657077

[8] Modarres, A., Hamedi, H. "Effect of waste plastic bottles on the stiffness and fatigue properties of modified asphalt mixes". Materials \& Design, 61, pp. 8-15. 2014. https://doi.org/10.1016/j.matdes.2014.04.046

[9] Mahrez, A., Karim, M. R. "Rheological evaluation of bituminous binder modified with waste plastic material". In: $5^{\text {th }}$ International Symposium on Hydrocarbons \& Chemistry (ISHC5), Sidi Fredj, Algers, 23-25 May 2010. https://core.ac.uk/download/pdf/11437409.pdf

[10] Tarefder, R. A., Zaman, M. "Design of neural networks for pavement rutting". In: Applied Research in Uncertainty Modeling and Analysis, (Attoh-Okine N. O., Ayyub B. M. (Eds.)). pp. 193-213. Springer, Boston, MA: 2005. https://doi.org/10.1007/0-387-23550-7_9

[11] Thodesen, C., Xiao, F., Amirkhanian, S.N. "Modeling viscosity behavior of crumb rubber modified binders". Construction and Building Materials, 23(9), pp. 3053-3062. 2009. https://doi.org/10.1016/j.conbuildmat. 2009.04.005

[12] Xiao, F., Amirkhanian, S. N. "Effects of binders on resilient modulus of rubberized mixtures containing RAP using artificial neural network approach". Journal of Testing and Evaluation, 37(2), pp. 1-10. 2008. https://doi.org/10.1520/JTE101834

[13] Gandhi, T., Xiao, F-P., Amirkhanian, S. N. "Estimating indirect tensile strength of mixtures containing anti-stripping agents using an artificial neural network approach". International Journal of Pavement Research and Technology, 2(1), pp. 1-12. 2009. https://doi.org/10.6135/ijprt.org. tw/2009.2(1).1

[14] Ozgan, E. "Artificial neural network based modelling of the Marshall Stability of asphalt concrete". Expert Systems with Applications, 38(5), pp. 6025-6030. 2011. https://doi.org/10.1016/j.eswa.2010.11.018

[15] Tapkın, S., Çevik, A., Uşar, Ü. "Prediction of Marshall test results for polypropylene modified dense bituminous mixtures using neural networks". Expert Systems with Applications, 37(6), pp. 4660-4670. 2010. https://doi.org/10.1016/j.eswa.2009.12.042

[16] Singh, D., Zaman, M., Commuri, S. "Artificial neural network modeling for dynamic modulus of hot mix asphalt using aggregate shape properties". Journal of Materials in Civil Engineering, 25(1), pp. 54-62. 2012. https://doi.org/10.1061/(ASCE)MT.1943-5533.0000548

[17] Awwad, M. T., Shbeeb, L. "The use of polyethylene in hot asphalt mixtures". American Journal of Applied Sciences, 4(6), pp. 390-396. 2007. https://doi.org/https://doi.org/10.12691/ajcea-1-5-2

[18] Arabani, M., Babamohammadi, S., Azarhoosh, A. "Experimental investigation of seashells used as filler in hot mix asphalt". International Journal of Pavement Engineering, 16(6), pp. 502-509. 2015. https://doi.org/10.10 $80 / 10298436.2014 .943132$ 
[19] Gokhale, S., Choubane, B., Byron, T., Tia, M. "Rut initiation mechanisms in asphalt mixtures as generated under accelerated pavement testing". Transportation research record: Journal of the transportation research board, 1940, pp. 136-145. 2005. https://doi.org/10.3141/1940-15

[20] AS.2891.12.1-1995. Methods of sampling and testing asphalt - Determination ofthe permanent compressive strain characteristics of asphalt - Dynamic creep test. 1995.

[21] Tardast, A., Rahimnejad, M., Najafpour, G., Ghoreyshi, A., Premier, G. C., Bakeri, G. "Use of artificial neural network for the prediction of bioelectricity production in a membrane less microbial fuel cell". Fuel, 117(A), pp. 697-703. 2014. https://doi.org/10.1016/j.fuel.2013.09.047

[22] Badrnezhad, R., Mirza, B. "Modeling and optimization of cross-flow ultrafiltration using hybrid neural network-genetic algorithm approach". Journal of Industrial and Engineering Chemistry, 20(2), pp. 528-543. 2014. https://doi.org/10.1016/j.jiec.2013.05.012
[23] Badday, A.S., Abdullah, A.Z., Lee, K-T. "Artificial neural network approach for modeling of ultrasound-assisted transesterification process of crude Jatropha oil catalyzed by heteropolyacid based catalyst". Chemical Engineering and Processing: Process Intensification, 75, pp. 31-37. 2014. https://doi.org/10.1016/j.cep.2013.10.008

[24] Tian, Z., Gu, B., Yang, L., Liu, F. "Performance prediction for a parallel flow condenser based on artificial neural network". Applied Thermal Engineering, 63(1), pp. 459-467. 2014. https://doi.org/10.1016/j. applthermaleng.2013.10.060

[25] Kebritchi, A., Jalali-Arani, A., Roghanizad, A.A. "Rheological behavior and properties of bitumen modified with polymeric coated precipitated calcium carbonate". Construction and Building Materials, 25(6), pp. 2875-2882. 2011. https://doi.org/10.1016/j.conbuildmat.2010.12.043 